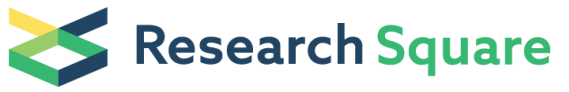 \\ Preprints are preliminary reports that have not undergone peer review. \\ They should not be considered conclusive, used to inform clinical practice, \\ or referenced by the media as validated information.
}

\section{A first principle simulation of adsorption behavior of HF, CS2 and COF2 on Au-doped anatase TiO2 (101)}

\section{Ling Nie}

Chongqing University of Science and Technology

Wei Li

Chongqing University of Science and Technology

Zhengqin Cao ( $\nabla$ caozhengqin@vip.sina.com )

Chongqing University of Science and Technology

Gang Hu

Chongqing University of Science and Technology

Qiang Yao

State Grid Chongqing Electric Power Company

Gang Wei

Chongqing University of Science and Technology

\section{Research Article}

Keywords: SF6, Au doping, Adsorption, Density function theory

Posted Date: February 17th, 2021

DOl: https://doi.org/10.21203/rs.3.rs-228316/v1

License: (c) (i) This work is licensed under a Creative Commons Attribution 4.0 International License.

Read Full License 


\section{Abstract}

$\mathrm{HF}, \mathrm{CS}_{2}$ and $\mathrm{COF}_{2}$ are three kind key partial discharge decomposition gas products of $\mathrm{SF}_{6}$ electrical insulation medium, which could be used for monitoring the type and degree of defect in gas insulated equipment. In this paper, the adsorption property including adsorption entropy change, adsorption distance, density of states, and frontier molecular orbitals, of $\mathrm{HF}_{2} \mathrm{CS}_{2}$ and $\mathrm{COF}_{2}$ on Au-doped anatase $\mathrm{TiO}_{2}$ (101) surfaces were simulated and analysis based on density function theory. The results demonstrated that $\mathrm{Au}-\mathrm{TiO}_{2}$ incentive upon $\mathrm{HF}, \mathrm{CS}_{2}$ and $\mathrm{COF}_{2}$ due to the little conductivity change and low adsorption entropy change, and this material could be not suitable to be used as a gas sensor for three decomposition gas detection in the application of condition monitoring and defect diagnosis in $\mathrm{SF}_{6}$ gasinsulated equipment based on DCA.

\section{Introduction}

Due to the excellent arc extinction properties $\mathrm{SF}_{6}$ has been widely used in gas insulated equipment as an insulating medium, [1-4]. However, $\mathrm{SF}_{6}$ would be decomposed to $\mathrm{HF}_{1} \mathrm{SOF}_{2}, \mathrm{H}_{2} \mathrm{~S}, \mathrm{CS}_{2}, \mathrm{COF}_{2}$ and so on with trace $\mathrm{H}_{2} \mathrm{O}$, trace $\mathrm{O}_{2}$, metal vapor, and organic solid insulation material in the gas insulated equipment [5-7] under partial discharge or local overheating fault, which would threaten the operation safety of power grid. The method of condition monitoring and defect diagnosis in $\mathrm{SF}_{6}$ gas-insulated equipment based on $\mathrm{SF}_{6}$ decomposition components analysis is an advantageous technique owing to its high sensitivity and capability to identify defect type, without being affected by electromagnetic interference [8-10].

Currently, due to the excellent functions and various modification methods of the metal oxide semiconductor system, objective achievements have been made in sensor applications. As a remarkably high catalytic property [11-13], the adsorption ability of the intrinsic and noble metal (such as $\mathrm{Au}, \mathrm{Pt}, \mathrm{Pd}$ et.al) modified anatase $\mathrm{TiO}_{2}$ (101) nanotubes for certain $\mathrm{SF}_{6}$ decomposition gases has been studied to estimate the possibility of such material as the chemical sensor in the application of condition monitoring and defect diagnosis in $\mathrm{SF}_{6}$ gas-insulated equipment [14-18]. The noble metal modified $\mathrm{TiO}_{2}$ system is proven to have the potential to be an excellent chemical sensor for $\mathrm{SO}_{2} \mathrm{~F}_{2}, \mathrm{SOF}_{2}$, and $\mathrm{SO}_{2}$ [19]. However, there are few studies about the detection of some key $\mathrm{SF}_{6}$ decomposition

components, namely $\mathrm{HF}, \mathrm{CS}_{2}$ and $\mathrm{COF}_{2}$, which are related to solid insulator and can more effectively represent the type and degree of defect in gas insulated equipment [19-23].

In the paper, the adsorption of Au doped anatase $\mathrm{TiO}_{2}(101)$ on $\mathrm{HF}, \mathrm{CS}_{2}$ and $\mathrm{COF}_{2}$ are investigated by first principle simulation based on density function theory (DFT). The parameters of adsorption property including adsorption entropy change, charge transfer, density of states, the distributions of highest occupied molecule orbital (HOMO) and lowest unoccupied molecule (LUMO) were simulated and 
analyzed. All this work provides the fundamental theoretical information of $\mathrm{TiO}_{2}$ nanotubes adsorbed $\mathrm{HF}$, $\mathrm{CS}_{2}$ and $\mathrm{COF}_{2}$.

\section{Materials And Methods}

All calculations were implemented in the Dmol3 model based on the density functional theory (DFT) [24]. The electron interaction effect was treated via the Perdew-Burke-Ernzerho (PBE) function of generalized gradient approximation (GGA), and the atomic orbital basis set was the double numerical plus polarization (DNP) [25]. Maximum force, energy tolerance accuracy, and maximum atom displacement were $0.002 \mathrm{Ha} / \AA, 1.0 \times 10^{-5} \mathrm{Ha}$, and $5 \times 10^{-3} \AA$, respectively [23]. The Brillouin zone was sampled as $2 \times 3 \times 1$ k-point grid through the Monkhorst-Pack method for the model [15]. The Tkatchenko and Scheffler's (TS) method was utilized for dispersion correction $[26,27]$. The self-consistent field convergence accuracy was $1 \times 10^{-6} \mathrm{Ha}$. In addition, the global orbital cut-off radius of $5.2 \AA$ and the smearing of $0.005 \mathrm{Ha}$ were employed to make sure the accurate results of total energy.

The adsorption entropy change of $E_{d}$ for $\mathrm{HF}, \mathrm{CS}_{2}$ and $\mathrm{COF}_{2}$. gas molecules adsorption system was defined as shown in formula (1) [28]:

$$
E_{d}=E_{g a s+s u r}-E_{g a s}-E_{s u r}
$$

where, $E_{\text {gastsun }} E_{\text {gas }}$ and $E_{\text {sur }}$ represent the total system energy after gas molecules adsorption on Au$\mathrm{TiO}_{2}$ surface, the energy of individual gas molecules, and the energy of insolated $\mathrm{Au}$ atom doped $\mathrm{TiO}_{2}$ surface, respectively. If the $E_{d}<0$, the energy is released in the process of gas adsorb on the Au- $\mathrm{TiO}_{2}$ surface, and If the $E_{d}>0$, the system will adsorb energy from the outside in the process.

The charge transfer in the process of adsorption was calculated via Mulliken charge population analysis [29]. If the Mulliken charge population $Q_{d}<0$, it denotes the electrons transfers from $\mathrm{Au}-\mathrm{TiO}_{2}$ surface to gas molecules during the process; If $Q_{d}>0$, it denotes the electrons transfers from gas molecules to Au$\mathrm{TiO}_{2}$ surface during the process.

The total density of states (TDOS), the partial density of states (PDOS), HOMO and LUMO were also analyzed to investigated the adsorption mechanism of $\mathrm{HF}, \mathrm{CS}_{2}$ and $\mathrm{COF}_{2}$. gas molecules on $\mathrm{Au}-\mathrm{TiO}_{2}$ surface.

\section{Results And Discussion}

\subsection{Adsorption distance, adsorption entropy change, and charge transfer of $\mathrm{HF}, \mathrm{CS}_{2}$ and $\mathrm{COF}_{2}$ on $\mathrm{Au}-\mathrm{TiO}_{2}$}


The optimized model and parameters (adsorption distance, adsorption entropy change, and charge transfer) of $\mathrm{HF}, \mathrm{CS}_{2}$, and $\mathrm{COF}_{2}$ on $\mathrm{Au}-\mathrm{TiO}_{2}$ surface are shown in Fig. 1-3 and Table 1.

Figure 2 shows the adsorption of $\mathrm{CS}_{2}$ molecules on $\mathrm{Au}-\mathrm{TiO}_{2}$ surface. There is also two adsorption modes were considered, that is $\mathrm{CS}_{2}$ approaches to $\mathrm{Au}-\mathrm{TiO}_{2}$ by $\mathrm{C}$ atom and $\mathrm{S}$ atom respectively. In $\mathrm{C}$ atom oriented system, $\mathrm{CS}_{2}$ molecule donates 0.093 e to $\mathrm{Au}-\mathrm{TiO}_{2}$ surface with the $-0.378 \mathrm{eV}$ adsorption entropy energy and $2.636 \AA$ adsorption distance. For $S$ atom oriented system, the $\mathrm{CS}_{2}$ gas molecule is also as the electrons donor and donate $0.116 \mathrm{e}$ in the adsorption process. The adsorption entropy change and adsorption distance are $-0.885 \mathrm{eV}$ and $2.669 \AA$.

As for $\mathrm{COF}_{2}$, three adsorption modes were considered, namely $\mathrm{C}$ atom, $\mathrm{F}$ atom, and $\mathrm{O}$ atom oriented system. In $\mathrm{C}$ atom oriented system, $\mathrm{COF}_{2}$ gas molecule donates 0.053 e electrons. The adsorption entropy change and adsorption distance are $-4.331 \mathrm{eV}$ and $3.633 \AA$. In $\mathrm{O}$ atom oriented system, the charge transfer and adsorption entropy change are the same as those in $\mathrm{C}$ atom oriented system, however, the adsorption distance of $2.618 \AA$ is smaller than that in $\mathrm{C}$ atom oriented system. In F atom oriented system, the adsorption entropy change and adsorption distance are $-2.228 \mathrm{eV}$ and $3.996 \AA$, and the gas molecule donated a few of electrons of $0.004 \mathrm{e}$.

Table 1

Adsorption parameters of $\mathrm{CS}_{2}$, and $\mathrm{COF}_{2}$ on $\mathrm{N}-\mathrm{TiO}_{2}$ nanotube surface

\begin{tabular}{|lllll|}
\hline $\begin{array}{l}\text { Gas } \\
\text { molecules }\end{array}$ & $\begin{array}{l}\text { Calculation } \\
\text { system }\end{array}$ & $\begin{array}{l}\text { Adsorption entropy } \\
\text { change }(\mathrm{eV})\end{array}$ & $\begin{array}{l}\text { Adsorption } \\
\text { distance }(\AA)\end{array}$ & $\begin{array}{l}\text { Charge } \\
\text { transfer (e) }\end{array}$ \\
\hline $\mathrm{HF}$ & $-\mathrm{H}$ & -0.368 & 3.266 & 0.044 \\
& $-\mathrm{F}$ & -0.368 & 2.636 & 0.043 \\
\hline $\mathrm{CS}_{2}$ & $-\mathrm{C}$ & -0.796 & 3.523 & 0.116 \\
& $-\mathrm{S}$ & -0.885 & 2.669 & 0.053 \\
\hline $\mathrm{COF}_{2}$ & $-\mathrm{C}$ & -0.431 & 3.633 & 0.053 \\
& $-\mathrm{O}$ & -0.431 & 2.618 & 0.043 \\
& $-\mathrm{F}$ & -0.228 & 3.996 & 0.004 \\
\hline
\end{tabular}

\subsection{The density of states of $\mathrm{HF}, \mathrm{CS}_{2}$ and $\mathrm{COF}_{2}$ on $\mathrm{Au}-\mathrm{TiO}_{2}$}

The DOS distribution of $\mathrm{HF}$ absorbed on $\mathrm{Au}-\mathrm{TiO}_{2}$ is shown in Fig. 4. Both TDOS distribution in $\mathrm{H}$ atom oriented system and $\mathrm{F}$ atom oriented system are similar to that of isolated $\mathrm{Au}-\mathrm{TiO}_{2}$ surface,it indicates that the number of surface electron transitions in this system is fewer. The only difference is a novel peak appears around $-11 \mathrm{eV}$ in the two oriented systems. As for the PDOS distribution, it could be confirmed that the $2 p$ orbital of $F$ atom mainly contributes to the new peak. In addition, the hybridization between $5 d$ 
orbital of Au atom and 2p orbital of F atom is weak, and the overlapping area is also very small near the Fermi level. This further indicates that the interaction between $\mathrm{Au}-\mathrm{TiO}_{2}$ and $\mathrm{HF}$ may be weak.

The DOS distribution of $\mathrm{CS}_{2}$ on Au doped $\mathrm{TiO}_{2}$ surface is exhibited in Fig. 5. one can observe the weak interaction between $\mathrm{CS}_{2}$ and $\mathrm{Au}-\mathrm{TiO}_{2}$ surface by the comparing TDOS distribution of $\mathrm{CS}_{2}$ adsorption system with that of isolated $\mathrm{Au}-\mathrm{TiO}_{2}$, where two TDOS distributions are basically similar to each other at the area near the Fermi level and the range among - $20 \sim-17 \mathrm{eV}$. But two novel peaks appear in $-15.5 \mathrm{eV}$ and $-9 \mathrm{eV}$ of $\mathrm{CS}_{2}$ adsorption system. In addition, it can find that the $2 p$ orbital of $C$ atom is the main contributor of the new peak at $-15.5 \mathrm{eV}$, and the $3 \mathrm{P}$ orbital of $\mathrm{S}$ atom is the main contributor of the new peak at $-9 \mathrm{eV}$. The $2 p$ orbital of $\mathrm{C}$ atom and the 3P orbital of $\mathrm{S}$ atom overlap evidently the $5 \mathrm{~d}$ orbital of $\mathrm{Au}$ among $-7.5 \sim-5 \mathrm{eV}$. Moreover, the overlapping peak between the $2 \mathrm{p}$ orbital of $\mathrm{C}$ atom and $5 \mathrm{~d}$ orbital of Au is little small than that between the 3P orbital of $S$ atom and $5 \mathrm{~d}$ orbital of $\mathrm{Au}$, which shows that the interaction between $\mathrm{CS}_{2}$ and $\mathrm{Au}-\mathrm{TiO}_{2}$ by $\mathrm{S}$ oriented system is more obvious.

The DOS distribution of $\mathrm{COF}_{2}$ on Au doped $\mathrm{TiO}_{2}$ surface is shown in Fig. 6. The TDOS distribution after $\mathrm{Au}-\mathrm{TiO}_{2}$ surface absorbing $\mathrm{COF}_{2}$ gas molecule also has a little change, especially among the Fermi level. Comparing with the TDOS distribution of isolated $\mathrm{Au}-\mathrm{TiO}_{2}$, four novel peaks appeared near $-14.5 \mathrm{eV}$, $-11.5 \mathrm{eV},-10.5 \mathrm{eV}$, and $-8.5 \mathrm{eV}$ in those of $\mathrm{C}$ atom and $\mathrm{O}$ atom oriented system. And four novel peaks appeared near $-13 \mathrm{eV},-11 \mathrm{eV},-9.5 \mathrm{eV}$, and $-8.5 \mathrm{eV}$ in that of $\mathrm{F}$ atom oriented system. According to the PDOS distribution, the overlapping area between the $2 \mathrm{p}$ orbital of $\mathrm{O}$ atom and $5 \mathrm{~d}$ orbital of $\mathrm{Au}$ is largest, followed by the one between the $2 p$ orbitals of $C$ atoms and the $5 \mathrm{~d}$ orbitals of $A u$, the one of between the $2 p$ orbitals of $\mathrm{F}$ atoms and the $5 \mathrm{~d}$ orbitals of $\mathrm{Au}$ is smallest.

\subsection{The $\mathrm{HOMO}$ and $\mathrm{LUMO}$ of $\mathrm{HF}, \mathrm{CS}_{2}$ and $\mathrm{COF}_{2}$ on $\mathrm{Au}-\mathrm{TiO}_{2}$}

Based on frontier molecular orbital theory, the energies of HOMO, LUMO, and the energy gap $E_{O}$ $\left(E_{O}=E_{L U M O}-E_{\text {HOMO }}\right)$ were obtained and exhibited in Table 2. It can observe that the HOMO and LUMO of isolated $\mathrm{Au}-\mathrm{TiO}_{2}$ are -4.4987 and $-4.4826 \mathrm{eV}$ respectively. The energy gap is $0.0161 \mathrm{eV}$.

As for $\mathrm{HF}$, the energies of $\mathrm{HOMO}$ and $\mathrm{LUMO}$ in $\mathrm{F}$ and $\mathrm{H}$ atom oriented systems are larger than those of isolated $\mathrm{Au}-\mathrm{TiO}_{2}$. And both the energy gaps in $\mathrm{F}$ and $\mathrm{H}$ atom oriented systems increase slightly in contrast to that of isolated $\mathrm{Au}-\mathrm{TiO}_{2}$. As for $\mathrm{CS}_{2}$, the energies of $\mathrm{HOMO}$ in $\mathrm{C}$ and $\mathrm{S}$ atom oriented system are 4.4806 and $-4.4725 \mathrm{eV}$ respectively. And the energies of LUMO in $\mathrm{C}$ and $\mathrm{S}$ atom oriented are -4.4623 and $-4.4488 \mathrm{eV}$ respectively. Consequently, both energy gaps for $\mathrm{CS}_{2}$ adsorption are a little larger than that of isolated $\mathrm{Au}-\mathrm{TiO}_{2}$. As for $\mathrm{COF}_{2}$, one can observe that the energies of $\mathrm{HOMO}$ in $\mathrm{C}$, $\mathrm{O}$, and $\mathrm{F}$ atom oriented system are $-4.4228,-4.4275$, and $-4.4737 \mathrm{eV}$ respectively. And the energies of LUMO in F, $\mathrm{O}$, and $\mathrm{C}$ atom oriented system are $-4.4035,-4.4094$, and $-4.4563 \mathrm{eV}$ respectively.

If the energy gap becomes larger, the conductivity of the system would decrease, while if the energy gap becomes smaller, the conductivity of the system becomes stronger [30]. So it could hypothesize that, to a 
large scale, the conductivity of $\mathrm{Au}-\mathrm{TiO}_{2}$ would be decreased after adsorbing $\mathrm{HF}, \mathrm{CS}_{2}$, and $\mathrm{COF}_{2}$. However, considering the little conductivity change and low adsorption energies, it could assume that this material is probably not suitable to detect the presence of $\mathrm{HF} \mathrm{CS}_{2}$, and $\mathrm{COF}_{2}$ precisely.

Table 2

HOMO and LUMO and relative energies for different absorption systems

\begin{tabular}{|lllll|}
\hline Calculation system & Adsorption system & HOMO/eV & LUMO/eV & |HOMO-LUMO|/eV \\
\hline $\mathrm{Au}^{-\mathrm{TiO}_{2}}$ & $/$ & -4.4987 & -4.4826 & 0.0161 \\
$\mathrm{CS}_{2}$ & C atom & -4.4806 & -4.4623 & 0.0184 \\
& S atom & -4.4725 & -4.4488 & 0.0237 \\
\hline $\mathrm{COF}_{2}$ & C atom & -4.4228 & -4.4035 & 0.0194 \\
& O atom & -4.4275 & -4.4094 & 0.0182 \\
& F atom & -4.4737 & -4.4563 & 0.0174 \\
$\mathrm{HF}$ & H atom & -4.4424 & -4.4218 & 0.0206 \\
& F atom & -4.4402 & -4.4221 & 0.0182 \\
\hline
\end{tabular}

\section{Conclusions}

In this paper, the adsorption parameters, namely adsorption entropy change, adsorption distance, DOS, and frontier molecular orbitals, of $\mathrm{HF}, \mathrm{CS}_{2}$, and $\mathrm{COF}_{2}$ gas molecules adsorption on Au doped anatase $\mathrm{TiO}_{2}$ (101) surface were simulated and analyzed to comprehensively investigating the gas sensitivity based on DFT. We found that the energies are released in the interaction of $\mathrm{HF}, \mathrm{CS}_{2}$, and $\mathrm{COF}_{2}$ absorbing on $\mathrm{Au}$ $\mathrm{TiO}_{2}$, and all the TDOS distribution of $\mathrm{HF}, \mathrm{CS}_{2}$, and $\mathrm{COF}_{2}$ are similar to that of isolated $\mathrm{Au}-\mathrm{TiO}_{2}$ surface. In addition, considering the little conductivity change and low adsorption entropy change, this material could be not suitable to be used as a gas sensor for the detection in the application of condition monitoring and defect diagnosis in $\mathrm{SF}_{6}$ gas-insulated equipment based on DCA.

\section{Declarations}

\section{Acknowledgements}

The authors appreciate the supported of science and Technology Research Program of Chongqing Municipal Education Commission (Grant No. KJQN202001524, Grant No. KJZD-K202001505), Chongqing Natural Science Foundation (cstc2020jcyj-msxmX0267)., Chongqing Research Program of Technology Innovation and Application Development (No. cstc2020jscx-msxmX0188) and Chongqing Market Supervision Administration Research Program (No. CQSJKJ2020008) 


\section{References}

1. Tang, J. et al. Correlation analysis between formation process of SF6 decomposed components and partial discharge qualities. IEEE Transactions on Dielectrics \& Electrical Insulation. 20, 864-875 (2013).

2. Mohamed, R. \& Michael, F. C. An assessment of eco-friendly gases for electrical insulation to replace the most potent industrial greenhouse Gas SF6. Environ. Sci. Technol. 52, 369-380 (2017).

3. Cui, H., Zhang, X., Chen, D. \& Tang, J. Adsorption mechanism of SF6 decomposed species on pyridine-like PtN3 embedded CNT: A DFT study. Applied Surface science. 447, 594-598 (2018).

4. Wang, Y. et al. Adsorption of SF6 decomposition components on Pt3 -TiO2 (101) surface: A DFT study. Appl. Surf. Sci. 459, 242-248 (2018).

5. Gui, Y., Liu, D., Li, X., Tang, C. \& Zhou, Q. DFT-based study on H2S and SOF2 adsorption on Si-MoS2 monolayer. Results in Physics. 13, 102225 (2019).

6. Sauers, I., Christophorou, L. G. \& Spyrou, S. M. Negative ion formation in compounds relevant to SF6 decomposition in electrical discharges. Plasma Chemistry \& Plasma Processing. 13, 17-35 (1993).

7. Ji, S., Zhong, L., Liu, K., Li, J. \& Ji, G. Research status and development of $\mathrm{SF}_{6}$ decomposition components analysis under discharge and its application. Proceedings of the CSEE. $35,2318-$ 2332(2015).

8. Ding, W., Hayashi, R., Ochi, K., Suehiro, J. \& Minagawa, T. Analysis of PD generated SF6 decomposition gases adsorbed on carbon nanotubes. IEEE Transactions on Dielectrics and Electrical Insulation. 13, 1200-1207 (2006).

9. Hu, W., Yu, L., Gui, Y. \& Zhang, X. First-principles study of SF6 decomposed gas adsorbed on Audecorated graphene. Applied Surface Science. 367, 259-269 (2016).

10. Lin, T., Han, D., Zhong, H., Jin, X. \& Zhang, G. Influence Factors of Formation of Decomposition ByProducts of SF6 in $50 \mathrm{~Hz}$ AC Corona Discharge. Transactions of China Electrotechnical Society. 29, 219-225 (2014).

11. Moon, J., Park, J. A., Lee, S. J., Zyung, T. \& Kim, I. D. Pd-doped TiO2 nanofiber networks for gas sensor applications. Sensors \& Actuators B Chemical. 149, 301-305 (2010).

12. Bamwenda, G. R., Tsubota, S., Nakamura, T. \& Haruta, M. Photo assisted hydrogen production from a water-ethanol solution: a comparison of activities of Au-TiO2 and Pt-TiO2. Journal of Photochemistry \& Photobiology A Chemistry. 89, 177-189 (1995).

13. Zeng, W. et al. Selective detection of formaldehyde gas using a Cd-doped TiO2-SnO2 sensor. Sensors. 9, 9029-9038 (2019).

14. Cao, Y. et al. CO2 adsorption on anatase TiO2 (101) surfaces: a combination of UHV-FTIRS and firstprinciples studies. Physical Chemistry Chemical Physics. 19, 31267-31273 (2017).

15. Zhang, X., Zhang, J. \& Dong, X. A DFT Calculation of Fluoride-Doped TiO2 Nanotubes for Detecting SF6 Decomposition Components. Sensors. 17, 14 (2017). 
16. Zhang, X., Dong, X. \& Gui, Y. Theoretical and experimental study on competitive adsorption of SF6 decomposed components on Au-modified anatase (101) surface. Appl. Surf. Sci. 387, 437-445 (2016).

17. Zhang, X. et al. TiO2 nanotube array sensor for detecting SF6 decomposition component SO2F2. High Voltage Engineering. 40, 1003-6520 (2014).

18. Wang, Y. et al. Adsorption of SF6 decomposition components on Pt3-TiO2(101) surface: A DFT study. Appl. Surf. Sci. 459, 242-248 (2018).

19. Zhang, X., Lei, Y., Jing, T. \& Dong, X. Gas Sensitivity and Sensing Mechanism Studies on Au-Doped TiO2 Nanotube Arrays for Detecting SF6 Decomposed Components. Sensors. 14, 19517-19532 (2014).

20. Zhong, L. et al. Decomposition Characteristics and Mechanism of SF6 Under Surface Defect on Solid Insulator. High voltage engineering. 44, 2977-2987 (2018).

21. Xiong, Q., Zhu, L., Zhong, L., Liu, K. \& Ji, S. Decomposition characteristics of SF6, under three typical defects and the diagnostic application of triangle method. IEEE Transactions on Dielectrics \& Electrical Insulation. 23, 2594-2606 (2016).

22. Zhang, X., Cheng, Z. \& Li, X. Cantilever enhanced photoacoustic spectrometry: Quantitative analysis of the trace H2S produced by SF6 decomposition. Infrared Phys. Technol. 78, 31-39 (2016).

23. Pan, J. et al. Decomposition characteristics of SF6 under thermal fault for temperatures below $400^{\circ} \mathrm{C}$. IEEE Transactions on Dielectrics \& Electrical Insulation. 21, 995-1004 (2014).

24. Delley, B. J. From molecules to solids with the DMol3 approach, Journal of Chemical Physics. Journal of Chemical Physics. 113, 7756-7764 (2000).

25. Cui, Z., Zhang, X., Li, Y., Chen, D. \& Li, Y. Theoretical study of SF6 decomposition on the MoS2 monolayer doped with Ag, Ni, Au, Pt: a first-principles study. Adsorption. 25, 225-233 (2019).

26. Perdew, J. P., Burke, K. \& Ernzerhof, M. Generalized Gradient Approximation Made Simple. Physical Review Letters. 77, 3865-3868 (1996).

27. Tkatchenko, A., Distasio, R. A., Head-Gordon, M. \& Scheffler, M. Dispersion-corrected Moller-Plesset second-order perturbation theory. The Journal of Chemical Physics. 131, 096106 (2009).

28. Boys, S. F. \& Bernardi, F. The calculation of small molecular interactions by the differences of separate total energies. Some procedures with reduced errors. Molecular Physics. 19, 553-566 (2002).

29. Mulliken, R. S. Electronic Population Analysis on LCAO-MO Molecular Wave Functions. II. Overlap Populations, Bond Orders, and Covalent Bond Energies. The Journal of Chemical Physics. 23, 18411846 (1955).

30. Hao, C., Zhang, X., Zhang, J. \& Ju, T. Adsorption behaviour of SF6 decomposed species onto Pd4decorated single-walled CNT: a DFT study. Molecular Physics. 116, 1749-1755 (2018).

\section{Figures}




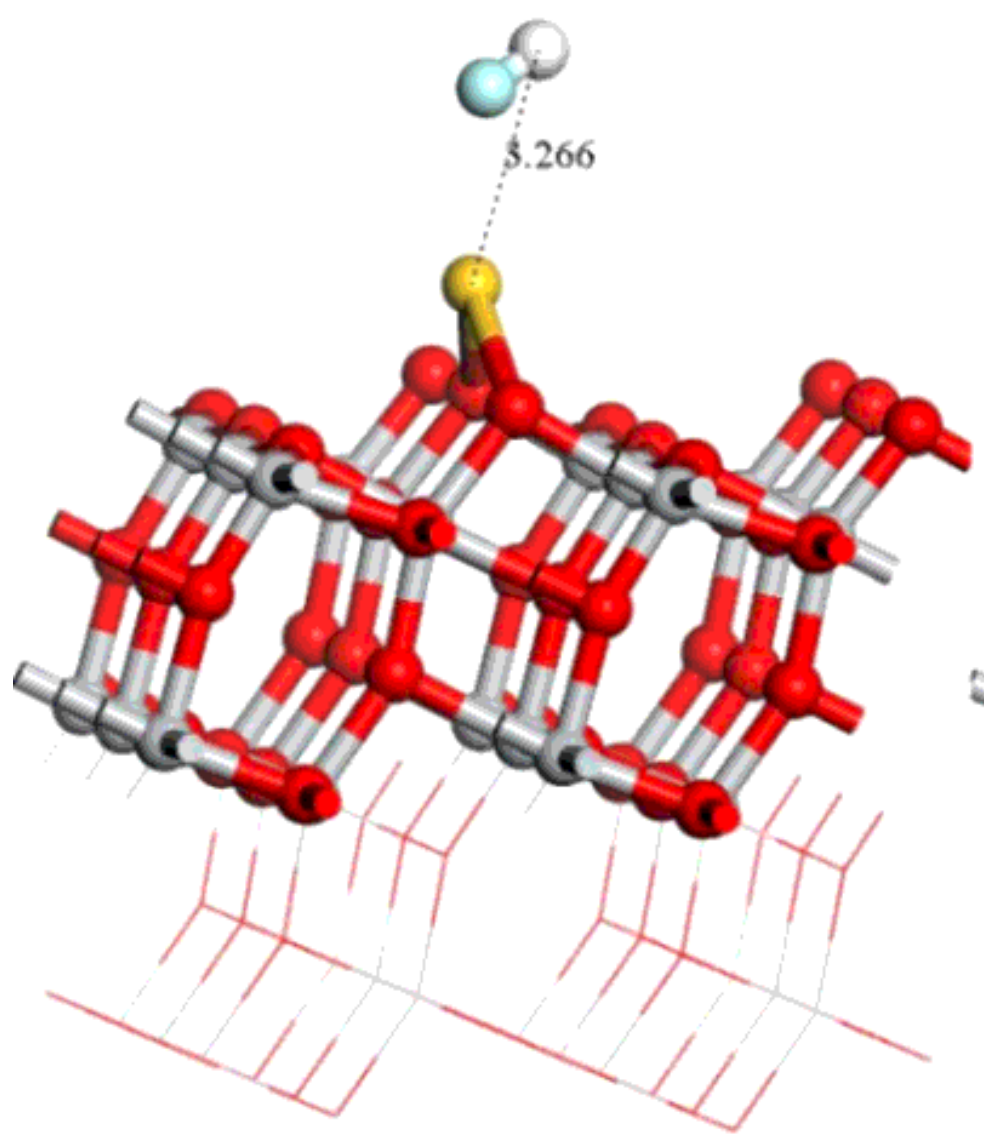

(a) $\mathrm{H}$ atom oriented system

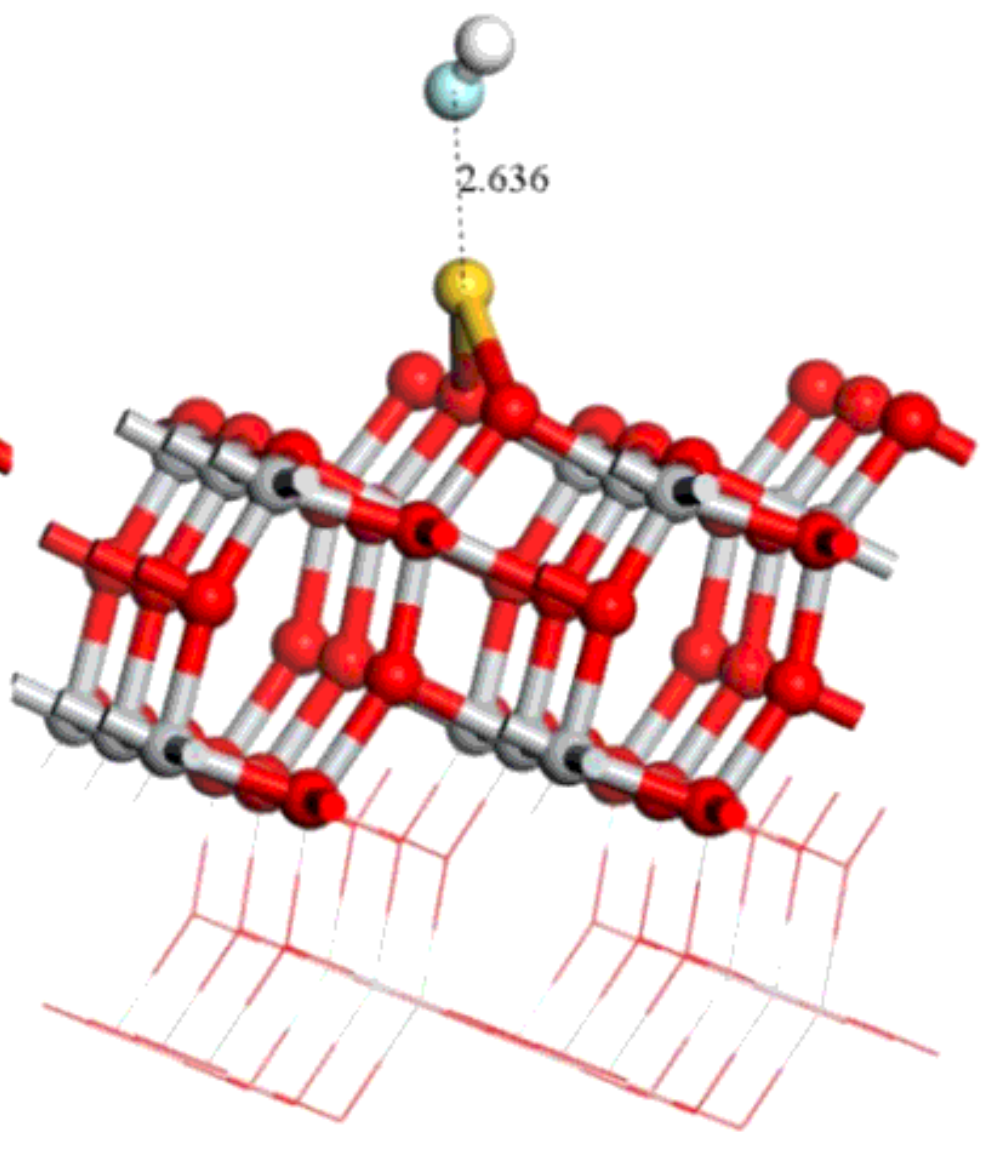

(b) $\mathrm{F}$ atom oriented system

Figure 1

Adsorption configuration of HF on Au doped TiO2 (101) surface ( $\mathrm{Ti}$ atom is gray, $\mathrm{O}$ atom is red, Au atom is golden, $\mathrm{F}$ atom is blue and $\mathrm{H}$ atom is white). 


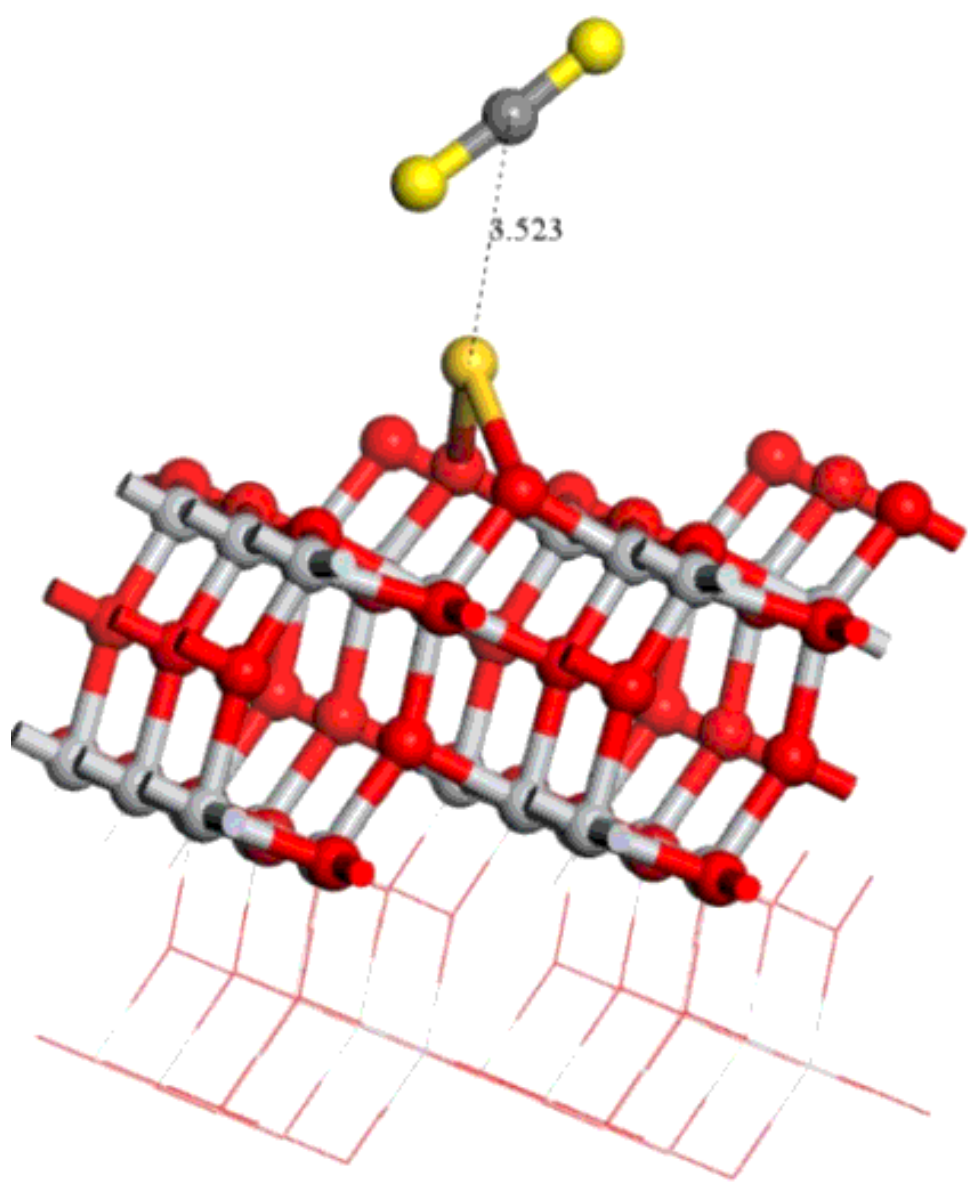

(a) C atom oriented system

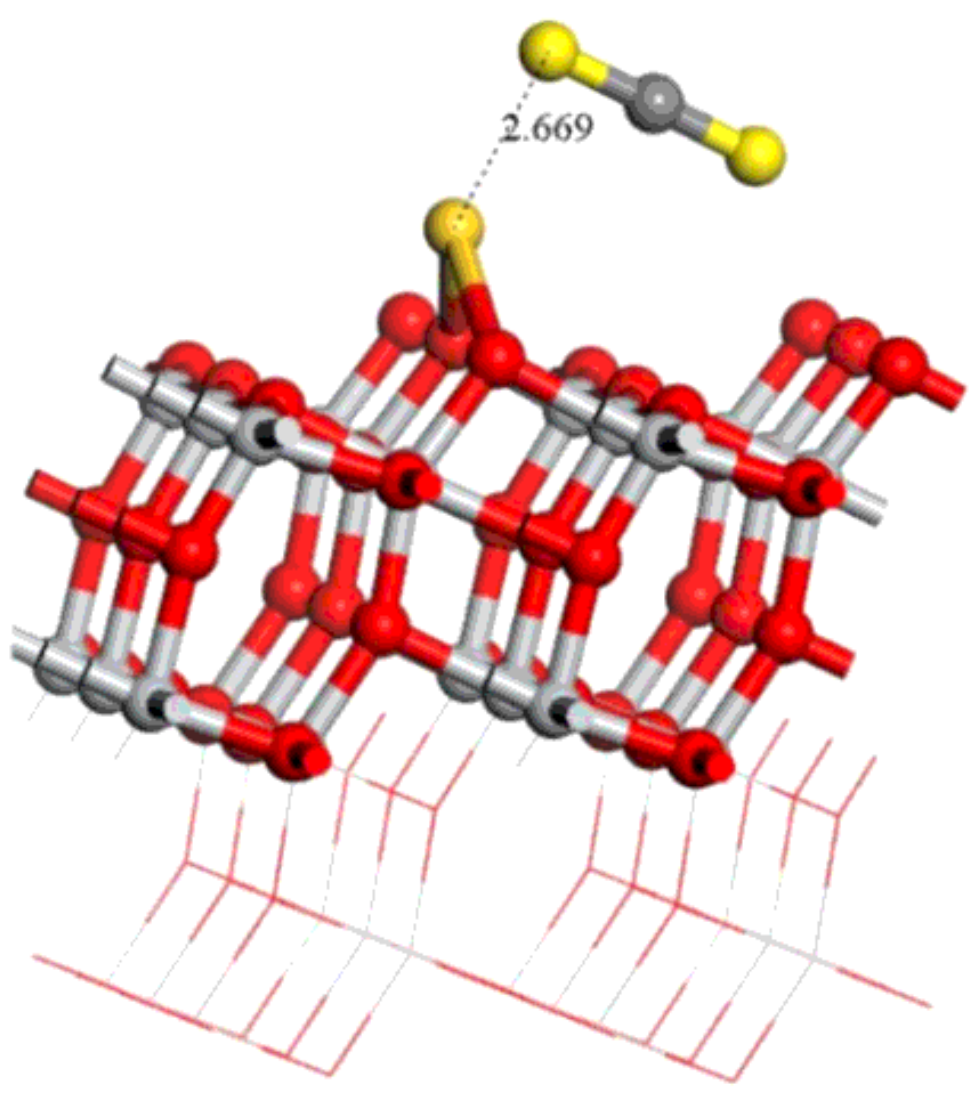

(b) S atom oriented system

Figure 2

Adsorption configuration of CS2 on Au doped TiO2 (101) surface (Ti atom is gray, $\mathrm{O}$ atom is red, Au atom is golden, $\mathrm{S}$ atom is yellow and $\mathrm{C}$ atom is dark gray) 


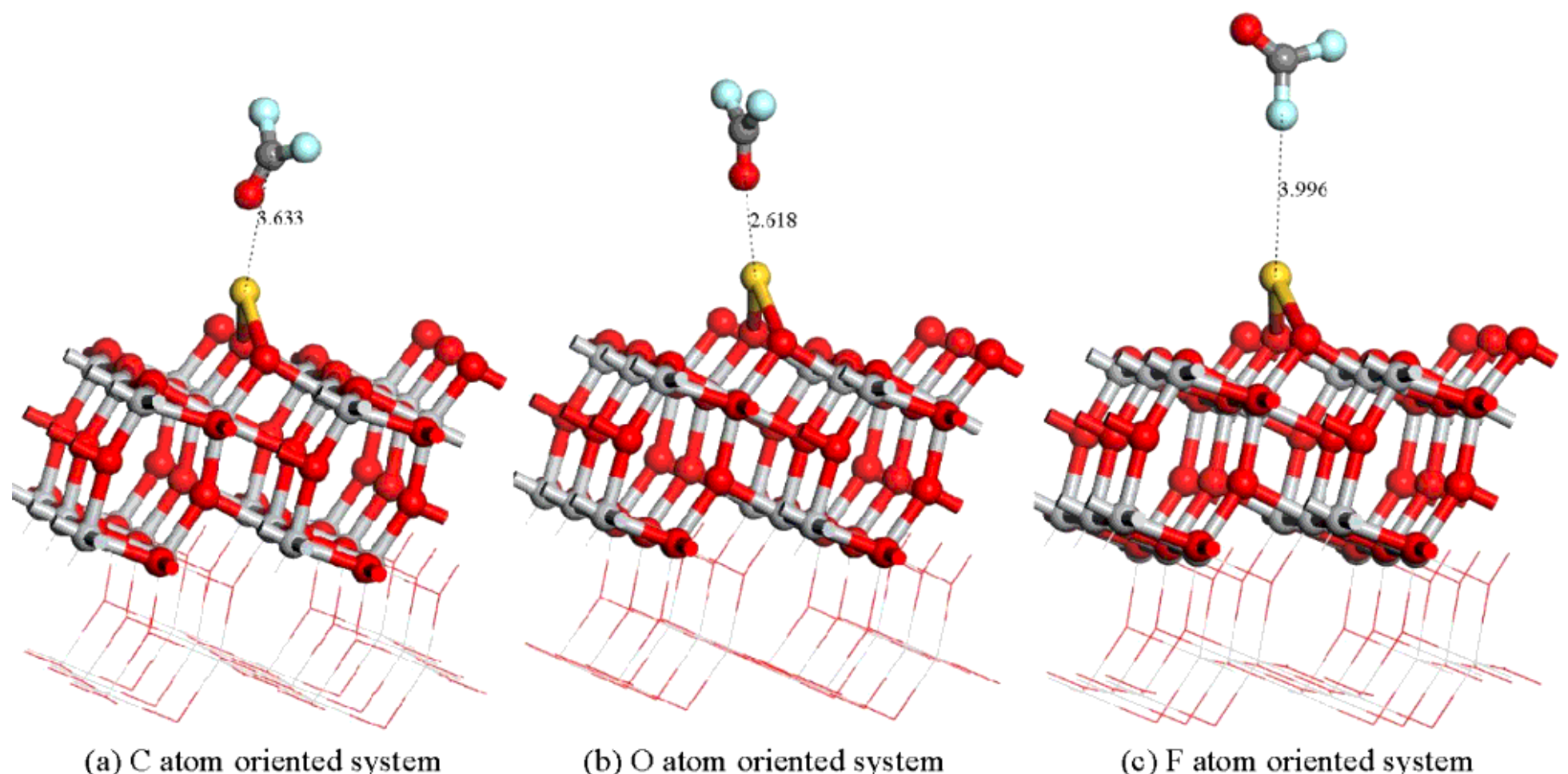

(a) C atom oriented system

(b) O atom oriented system

(c) F atom oriented system

Figure 3

Adsorption configuration of COF2 on Au doped TiO2 (101) surface (Ti atom is gray, $\mathrm{O}$ atom is red, $\mathrm{Au}$ atom is golden, $\mathrm{F}$ atom is blue and $\mathrm{C}$ atom is dark gray) 


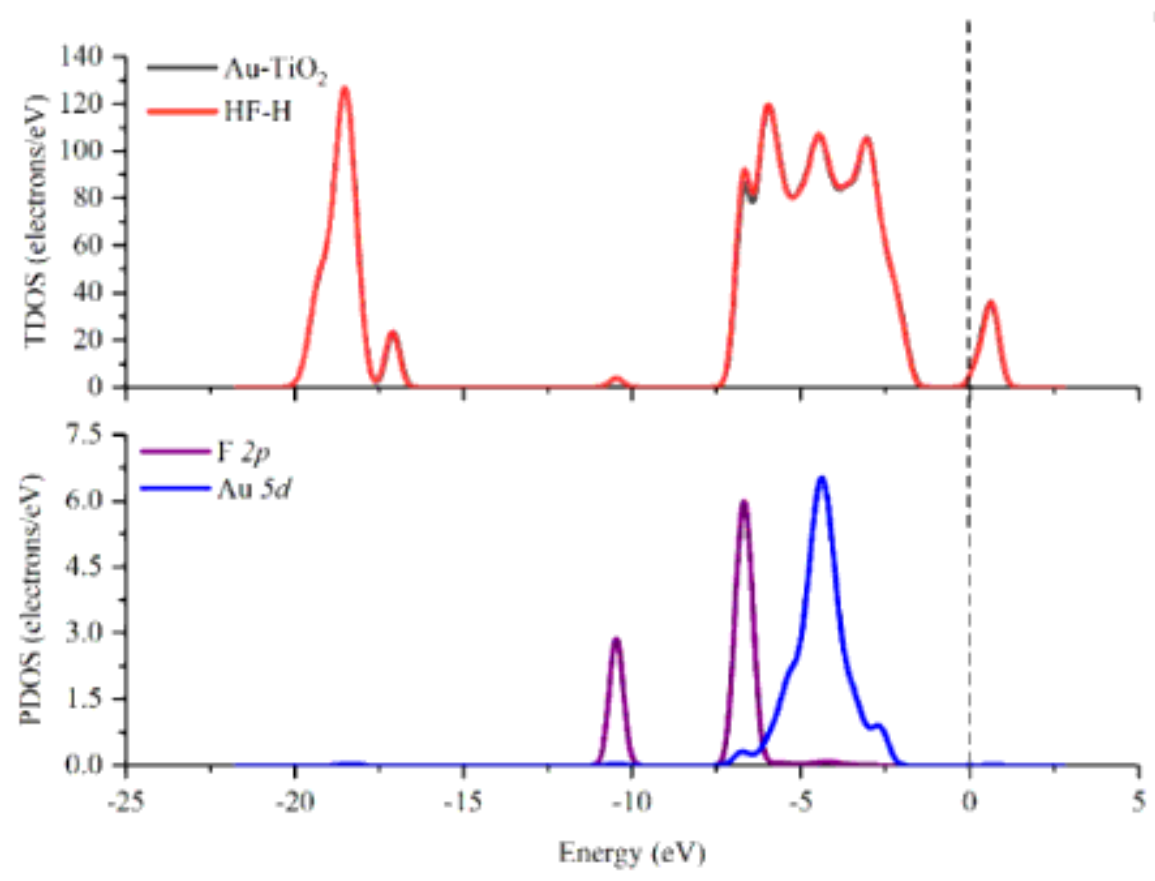

(a)

(b)

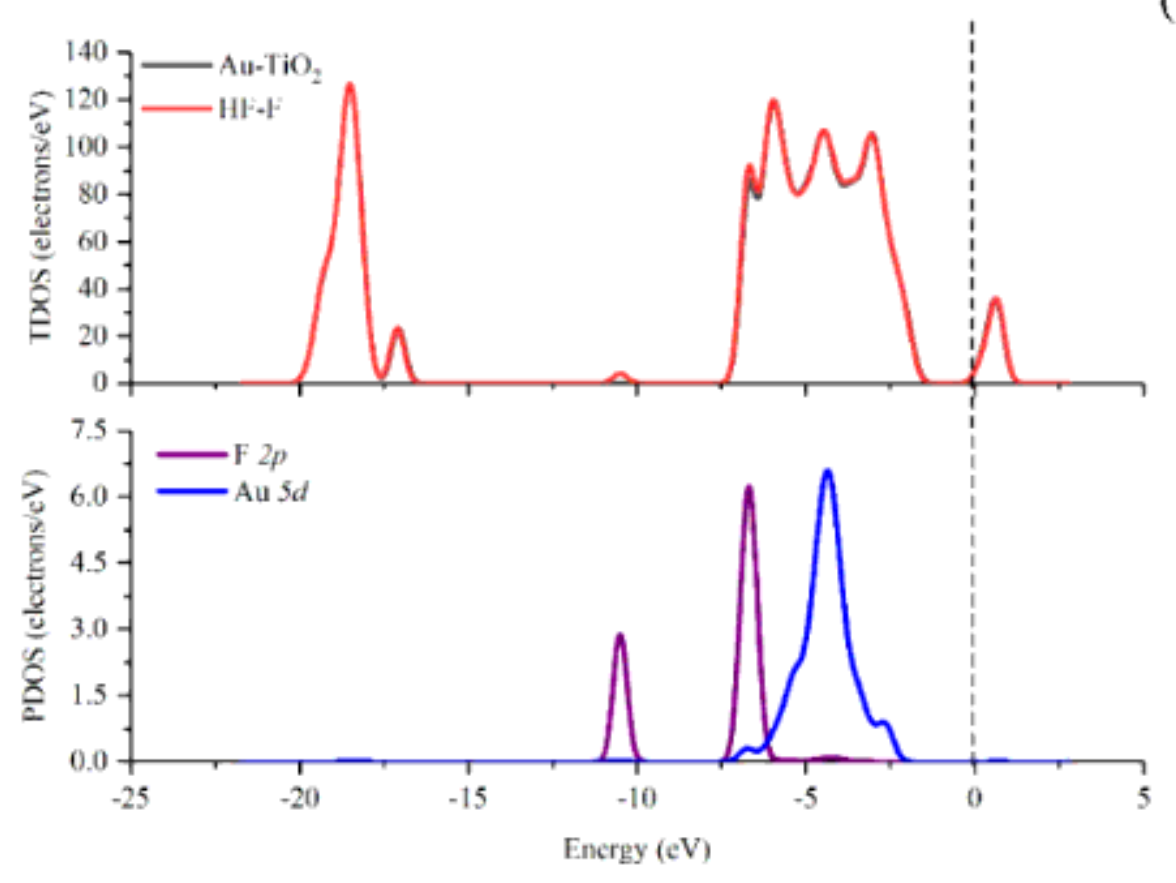

Figure 4

TDOS and PDOS distribution of HF molecule absorbed on Au doped TiO2 (101) surface 


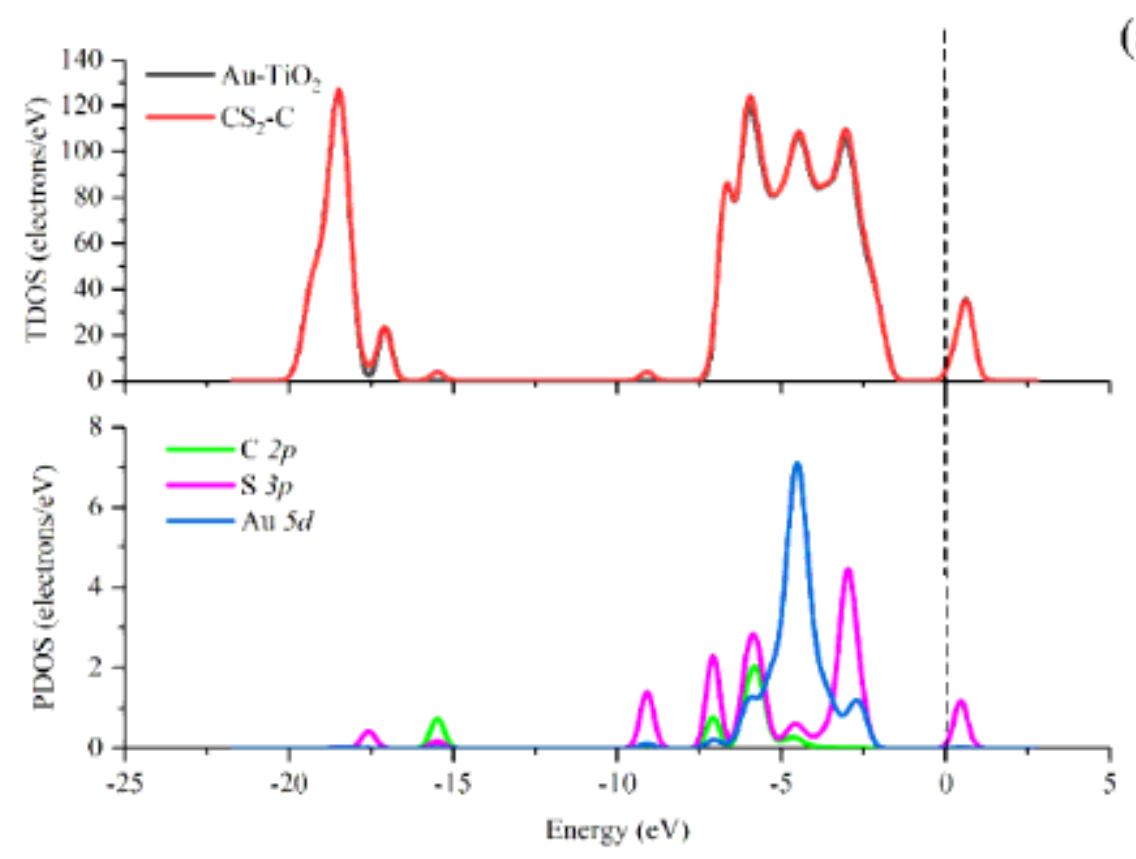

(a)

(b)

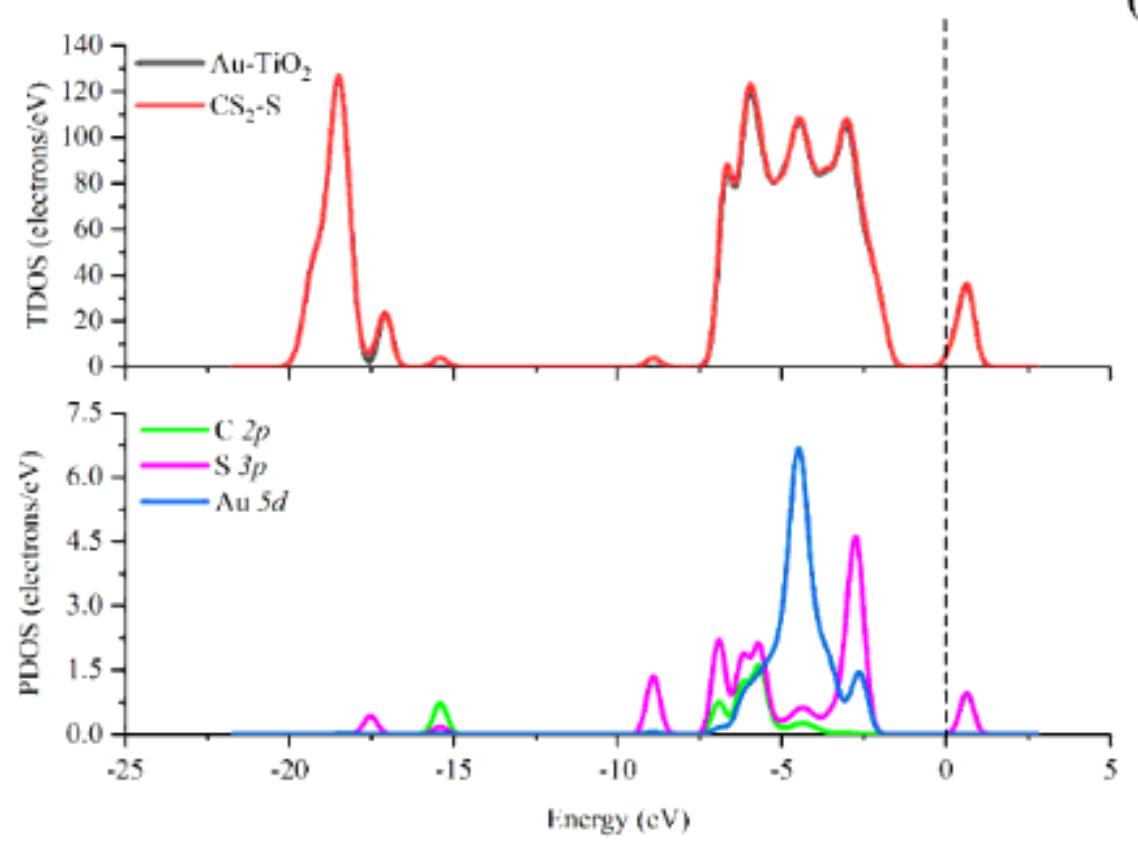

Figure 5

TDOS and PDOS distribution of CS2 molecule absorbed on Au doped TiO2 (101) surface 


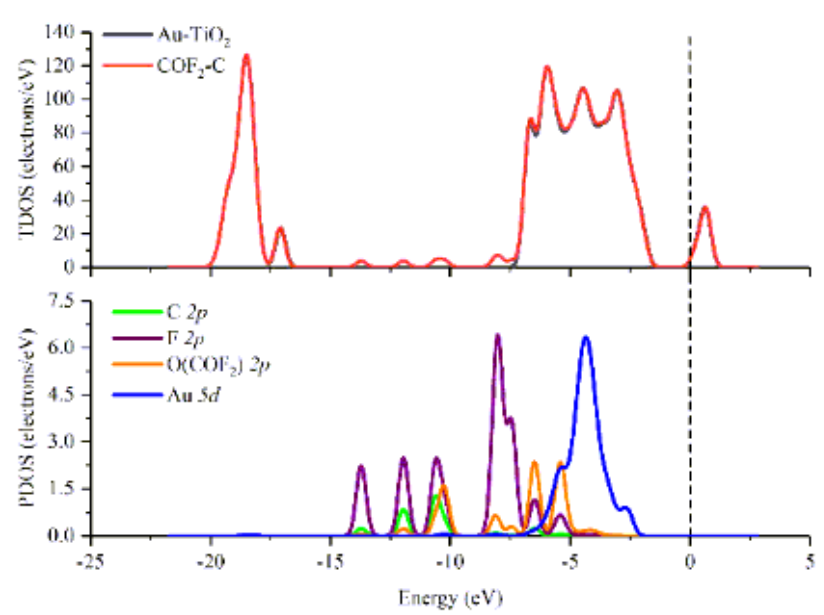

(a)

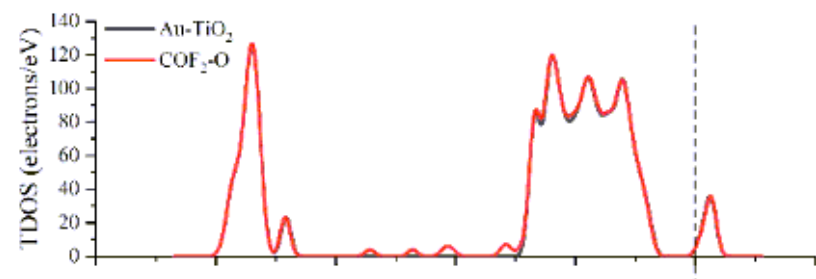

(b)
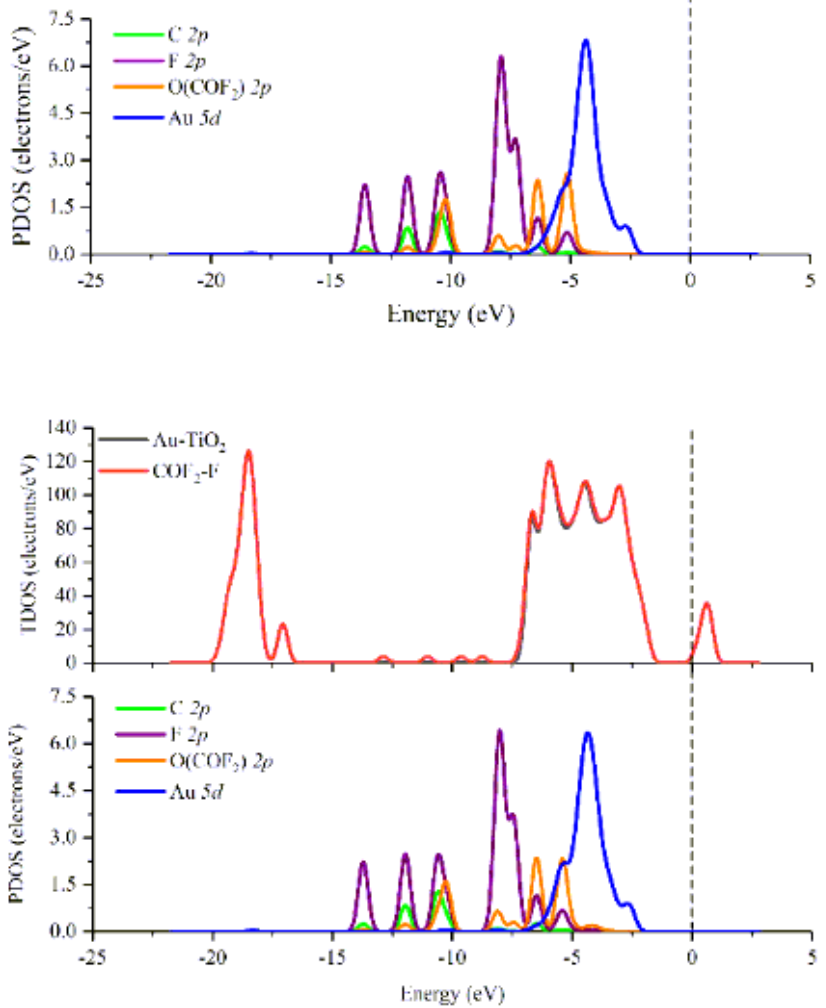

(c)

\section{Figure 6}

TDOS and PDOS distribution of COF2 molecule absorbed on Au doped TiO2 (101) surface 